\title{
Experiential Learning Through a Week-Long Information Systems Case Study
}

\author{
Madison Corbin \\ Brigham Young University \\ madss33@byu.edu
}

\author{
Cherileigh Leavitt \\ Brigham Young University \\ cleavit6@byu.edu
}

\author{
Degan Kettles \\ Brigham Young University \\ degan.kettles@byu.edu
}

\author{
Greg Anderson \\ Brigham Young University \\ profganderson@byu.edu
}

\begin{abstract}
An experiential learning model known as INTEX (INTegrative EXercise) was implemented by the Information Systems Department at Brigham Young University. The purpose was to facilitate a team-based holistic learning experience in both content and application to supply a means of measuring student performance and further program development. In this paper, we explain how INTEX presents an adoptable experiential learning model, how INTEX is administered, and the extent to which INTEX fulfills each of its seven objectives based on student, alumni, and faculty feedback. Our main findings are: INTEX provides a compelling real-world case simulation, gives students an invaluable teamwork experience, facilitates the development of both technical and soft presentation skills, and furnishes a reference point for students to utilize in their careers. It also serves as a means of measuring program performance that can be used to further IS curriculum development.
\end{abstract}

\section{Introduction}

It has been over 20 years since Brigham Young University's Information Systems (IS) department implemented a project-based learning module known as INTEX (INTegrative EXercise). Although technology needs and skills have evolved during that time, the objectives of this integrative exercise have remained constant in continuing to provide an invaluable teamwork experience, an opportunity for students to reinforce skills competency, a positive learning experience, and a means to measure program performance.

INTEX is a week-long experience in which students work in four-person teams to develop a technical solution for a given business case. Extensive faculty discussion and coordination with industry representatives preceded the development of this exercise, leading to the identification of the main objectives for INTEX:

1. Demonstrate, through hands-on experience, a comprehensive view of how principles are synergistically applied to a real-world case
2. Solve a problem requiring significant teamwork, simulating an "on-the-job" environment

3. Create an opportunity for students to practice both technical skills and soft presentation skills

4. Provide students with performance feedback

5. Create an experiential learning activity reinforcing skills competency

6. Establish a measurement of comprehensive student learning for faculty

7. Provide feedback to IS faculty for further curriculum development

The intent of this paper is to demonstrate the extent to which INTEX fulfills the aforementioned objectives and provides the necessary information so that other institutions might consider implementing a similar integrative experience to benefit their students.

As part of this research, feedback was gathered from current IS students at the university, IS alumni, and IS faculty. This paper is formatted as follows: an explanation of the theoretical underpinning for INTEX; a description of how the exercise is implemented; and an assessment of how well it is perceived to meet its objectives. Lastly, alternative approaches and potential additions to improve INTEX are considered.

\section{Experiential Learning}

The primary objective of INTEX is to provide a learning experience that requires a collaborative faculty effort to gather learning outcomes and competencies from all courses taught in the semester's curriculum into one week-long case, providing students a teambased experiential learning project to solve. This objective is derived from experiential learning theory, which heavily influenced the design of the exercise.

\subsection{The Need for a Holistic Approach}

In the 2018 Employer Research Report, the American Association for Colleges \& Universities announced, "Both [executives and hiring managers] value applied experiences and real-world skills, but only $33 \%$ of executives and $39 \%$ of hiring managers think that recent graduates are very well prepared to 
apply knowledge and skills to real-world settings" [2]. What explains the gap between academic learning and workforce application? In 1984, David A. Kolb suggested a different view of learning through his experiential learning theory. The theory is based on several key assumptions evolving from his personal work as well as common characteristics derived from learning models created by Lewin, Dewey, and Piaget [7]. Among these assumptions are the following: learning is not a collection of facts or habits, but rather a process through which ideas are formed and reformed; learning occurs in the interplay between expectation and experience; the varying approaches to learning pose conflicts, and learning is the result of resolving those conflicts; learning is a holistic process of adaptation to the world [7].

The overarching purpose of the experiential learning theory is to propose an integrative approach to learning that "combines experience, perception, cognition, and behavior" [7]. "When learning is conceived as a holistic adaptive process, it provides conceptual bridges across life situations such as school and work, portraying learning as a continuous, lifelong process" [7]. These conceptual bridges are built by implementing four stages that Kolb outlines in his theory.

\subsection{Kolb's Experiential Learning Theory}

Kolb and his predecessors saw the need to breach the gaps between the "opposing ways of dealing with the world" [7] and identified two main conflicts: the conflict between concrete experience and abstract concepts, and the conflict between observation and action.

The experiential learning cycle, as shown in Figure 1, comprises these four learning abilities, and "the learner must go through the entire cycle" [9] in order to effectively bridge the gap. However, learners may enter the cycle at any stage.

The four stages can be grouped into two types of experiences: transforming and grasping. Transforming experiences portray a symbolic representation of new information in which students analyze and internally process it as well as observe and reflect on the active experimentation of others [9]; active experimentation and reflective observation are considered transforming experiences. Grasping experiences can be identified as ones that produce "concrete qualities of the world" and necessitate the learner's reliance on his/her senses [9]; concrete experience and abstract conceptualization fall under the grasping category.

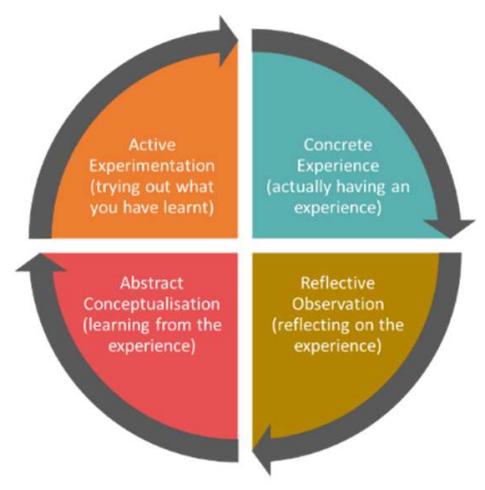

\subsection{Experiential Learning in IS and INTEX}

Several educational institutions have adopted experiential learning modules to supplement employee training and student learning. For example, Boston College implemented a 10-week consulting case competition in their Management Information Systems course [6]; Dalhousie University in Nova Scotia used a gaming and simulation approach to solidify IT management principles [1]; and in an enterprise systems course at King Faisal University in Saudi Arabia, Fathelrahman and Kabbar used case studies and fieldwork experience to facilitate experiential learning [5].

INTEX offers yet another experiential learning approach in the information systems discipline that is unique in its scope, time frame, and deliverables. It is a simulation of a realistic consulting project which requires the learner to move through each of the four steps in Kolb's model in order to successfully complete the case (see Figure 2).

2.3.1. Concrete Experience. Through concrete experiences, learners are immersed "in the immediacy of the moment" and consequently depend on their "intuitive and affective responses" [4]. In INTEX, students must develop a solution for the consulting project in one week, which requires applying, simultaneously, the programming, database, project management, and systems architect principles they've learned throughout the semester. This involves outlining workflows and diagrams, creating a web app, designing and building a database, constructing a project management plan, performing a feasibility analysis, and proposing the designed solution to judges. 2.3.2. Reflective observation. Reflective observation, "a willingness to patiently consider many alternatives" [4], occurs immediately after presenting to the judges. The judges give constructive criticism to the students on both their presentation and their solution.

Figure 1. Kolb's experiential learning model [8] 
2.3.3. Abstract conceptualization. Abstract conceptualization "calls for logical thinking and rational evaluation to create...logically sound theories" [4]. In INTEX, students transform their reflective observation into identifiable concepts as they complete a self- and peer-evaluation, as well as when they complete the debriefing. These evaluations ask them to articulate what they learned and what they would do differently if given the opportunity.

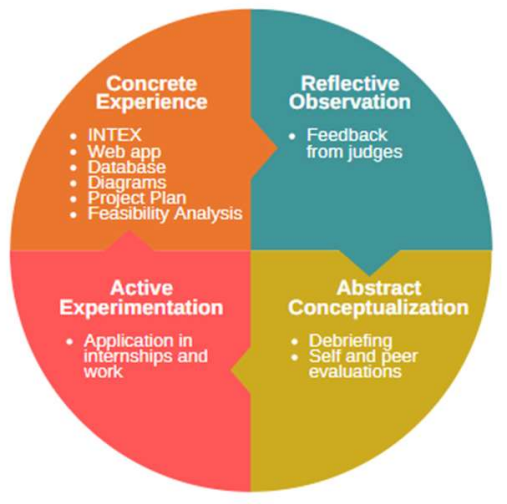

Figure 2. How INTEX exhibits Kolb's experiential learning model

2.3.4. Active experimentation. Active experimentation requires that the student take a risk and participate "with an emphasis on pragmatically testing previously generated concepts" [4]. Students are able to leverage the skills they learn in INTEX in their current as well as future jobs and internships.

Following is a more complete description of the application of INTEX.

\section{How INTEX is Organized}

INTEX is a week-long case study that takes place near the end of each semester during the junior year of an Information Systems program. In four-person teams, students work intensely to analyze a challenging business problem and propose a solution, including a functional prototype, in only four days. A successful and timely solution requires that students work together as teams and strategically interweave the concepts learned that semester. No IS junior classes are held during the week of INTEX.

\subsection{Pre-INTEX}

3.1.1. Courses. Juniors in the Information Systems program at Brigham Young University are required to take an envelope of 12.0 credit hours (four classes) each semester of solely IS courses. Depending on the semester these courses might include a combination of systems analysis and design, machine learning, database design, project management, cybersecurity, principles of business programming, networking, and enterprise app development. The core concepts of the courses create the framework for the system requirements of the INTEX case each semester.

3.1.2. Teams. When admitted to the IS program, students are assigned to a four-person team for the duration of the semester, including during INTEX.

3.1.3. Faculty Preparation. In the weeks leading up to INTEX, one faculty member is designated as a coordinator. With the help of other faculty members in the department, the coordinator manages the selection of a business case. They also assist faculty in creating a grading rubric for the case, which is used by teaching assistants (TAs), that involves the skills from each of the courses. The coordinator also works with department and school staff to reserve rooms for presentations, communicates with the industry judges for the event, establishes awards and certificates for students, and organizes and manages the group of TAs to grade the submitted "hard copy" projects. Lastly, the coordinator oversees any instructions or communication (including documentation, such as the schedule) that will be provided to the students regarding INTEX.

3.1.4. Preliminary Information. At the beginning of each semester, students are informed that they can anticipate spending 40-60 hours over four days working on their upcoming INTEX project. Consequently, their IS junior classes are cancelled that week, and students are strongly encouraged to take work off in order to contribute fully to their team. Faculty members remind students of this time commitment periodically throughout the semester in order to give students ample opportunity to communicate with employers.

3.2.1. Schedule \& Kickoff. On the Monday of INTEX week, students gather for the kickoff meeting. They're given the case, schedule, and expected deliverables; the grading requirements are also explained. All students are expected to turn in their deliverables by that Friday at 11:00 AM. The groups are informed that they will present the results of their INTEX work to a panel of judges and are randomly assigned a presentation time for Friday. This provides an opportunity for students to rehearse their INTEX presentation throughout the week.

3.2.2. Case. Students are given a case involving a real business problem provided by industry professionals or built from previous consulting projects faculty members have encountered. Cases vary from year to year in regard to industry and system requirements; however, the commonality between all cases is the need for a new system to solve a business need. The typical project encompasses diagramming new processes, 
creating a database, building software prototypes, identifying controls, proposing hardware requirements, etc. Examples of past cases include improvements or business needs to be met for a dehydrated food processing company, a sports equipment retail company, a regional airline system, a chemistry lab, and a charity campaign [10].

3.2.3. Collaboration. As mentioned previously, students are in four-person teams for INTEX which are the same teams they have been in throughout the semester. There is no instruction given on how to break down the tasks needed to complete the project; each team decides amongst themselves how they will divide the work. For example, some teams may choose to have two members create the database and the software program, focusing on the prototype while the other two members focus on the reports and diagrams. Other teams may choose to have each member work separately on a segment of each deliverable. A team might assign a member to be the project manager who makes sure other members complete required tasks on time and meet objectives. Completing a project with such breadth and limited time requires that teammates rely on and communicate with each other. They cannot complete it independently.

3.2.4. Communication. Questions often arise regarding the specifics of deliverables or seeking clarification about the case. Professors and teaching assistants are able to answer questions for the first two days, acting as sponsors for the project. Slack, an instant messaging platform, is used as the main means of communication with sponsors. Questions are answered publicly to ensure that each team is given the same information, and none are left at an advantage/disadvantage. These questions are usually clarifying questions regarding INTEX requirements. Sponsors do not provide answers to questions that specifically seek how to solve the problem. Students are expected to use their own creativity to develop a unique solution. After the first two days, the acting sponsors are "out of town," and unable to answer questions, giving students a glimpse of potential challenges in workforce in that one cannot always expect an immediate answer when working on a project. Faculty have to exercise caution in how questions are answered. Many students ask specific questions to have faculty confirm a proposed solution for their group. In order for the project to achieve the stated objectives, faculty need to take the approach of an inexperienced sponsor with a minimal technological background in order to allow students to create their own ideas and solutions.

3.2.5. Deliverables. The list of deliverables is determined by faculty and is based on desired learning outcomes and competencies for courses taken in a given semester. For example, if the courses taken in a semester are project management, database design, systems analysis and design, and introduction to business programming, the following are a list of deliverables the students would be required to deliver:

Project Report. The project report includes an assessment of the current operations of the company, diagrams describing current business activities and processes, an explanation of the proposed solution, diagrams of the new system, and finally, a feasibility

analysis outlining the organizational, technical, and economic implications of building the proposed system.

Prototype. A prototype for the new system must be built and turned in along with a database diagram and schema. Faculty can determine the level of completion for the prototype such as a wireframe design, a fully functional application, partially functional, etc.

Project Management \& Implementation Plan. Using project management software, typically Microsoft Project, students build a schedule for implementing their proposed system along with cost estimates

Presentation. Groups are assigned an afternoon time on Friday after submission of their project to present to a panel of judges in a reserved room on campus. There are multiple rooms that are used for judging so that multiple teams can be evaluated separately during each time slot. The evaluation team consists of one faculty member, an outside professional, and a graduate student who is typically a current teaching assistant (TA) for one of the IS courses. The timeframe for each presentation is as follows:

Presentation \& Questions - 25 minutes

Deliberation - 5 minutes

Feedback - 10 minutes

3.2.6. Turning in the project. All deliverables, excluding the presentation, are turned in digitally via a learning management system on Friday morning before the presentation. A printed version of the project report must also be turned in on Friday morning. Teaching assistants will use these deliverables to help assess grades. 
Report Organization (15 pts)

- Professional format, graphics, and writing; executive summary, problem description, and conclusions are well-organized, descriptive, and complete; electronic version of report submitted as required

Business Processes \& Controls (15 pts)

- Controls to mitigate fraud; recovery/backup; controls for information input/output; control frameworks and IT audit

- Major business cycles (i.e., revenue, expenditure, production) and how the proposed system will impact them

System Solution (20 pts)

- Project Charter; feasibility and risk analyses; Gantt Chart/WBS in MS Project is clear; deployment recommendations

- Discussion of proposed methodology (i.e. Agile, waterfall); use case, activity, and class diagrams with descriptions; consistent with the SSDs; sample reports use best practices for controls and information organization

\section{Website Solution (15 pts)}

- User interface is intuitive and professional; ASP.NET MVC site navigation functions properly

Database Design (15 pts)

- Database diagram meets case requirements; SQL Script database complete with correct primary/foreign key constraints

Written Report Score: __/80 pts Presentation Score (separate rubric): __/20 pts

Figure 3. Sample of INTEX grading rubric

\subsection{Post-INTEX}

3.3.1. Peer Evaluations \& Student Feedback. After presenting, each student, as part of their grade for INTEX, is required to fill out a private peer evaluation form. The evaluations capture the level of participation from each member of the group. Students are also asked to reflect on areas such as what did and didn't work well, suggestions for INTEX improvement, principles learned, and the value of the exercise.

3.3.2. Awards. The Monday following INTEX, students meet during their regularly scheduled class time, and winners are announced. The winning teams are sometimes given a cash prize/gift card from an industry sponsor. Other awards are given to the remaining groups and are intended to be humorous, providing entertainment and adding to the experience. For example, the "three marketeers" award goes to the group who have an above-average talent in their salesmanship during their presentation. Another example is the best implementation for the created application. However, none of the awards are intended to degrade the student's work. While there are no added points for "winning" INTEX, a competitive aspect increases motivation to do well for many of the students.

3.3.3. Grading. The project is worth a significant amount and the grading rubric consists of different parts that feature both the presentation component and the components related to the four semester IS courses enrolled by students. Grading on the individual components, such as database design, is primarily performed by TAs of the respective IS courses. TAs are assigned a specific area to grade for each area of INTEX so as to try to establish a level of consistency. Each component's rubric is defined by the faculty member teaching the course and evaluates the learning objectives and competencies established for the course. Many TAs participate in the grading under the supervision of faculty who have prepared the rubric (see Figure 3). TAs attempt to complete all the grading in a single evening. Faculty perform a quality check on the grading and make any needed adjustments before announcing grades the following week.

3.3.4. Faculty Review. After grading has been completed by the TAs, faculty members review the grades for consistency and look for any grading anomalies or outliers. Faculty confirm that assigned grades are fair, taking into account that many students spent between 40-60 hours working on this project, with the understanding that INTEX is supposed to provide a positive experience for what a project might feel like in the "real world".

\section{Assessment of INTEX Effectiveness}

The effectiveness of INTEX at meeting its seven objectives, as listed in the introduction, was measured using surveys from current IS students, alumni, and professors that participated in INTEX. It also was measured using additional feedback provided in student peer evaluations.

\subsection{Student Assessment of INTEX}

Students were surveyed asking for indication as to how INTEX enhanced the development of the top ten skills current employers seek in new college graduates published by the Association of American Colleges \& Universities (AACU) (see Table 1) [3]. The students ranked how INTEX impacted their development of these skills based on the following scale: $1=$ Not enhanced, 2 = Slightly enhanced, $3=$ Enhanced, $4=$ Greatly enhanced. The number contained in parentheses is the standard deviation. 
Table 1. Student/alumni survey of INTEX impact on top 10 desired employee skills

\begin{tabular}{|c|c|c|c|}
\hline & AACU Top 10 Skills & $\begin{array}{l}\text { Student } \\
\text { Mean }\end{array}$ & $\begin{array}{l}\text { Alumni } \\
\text { Mean }\end{array}$ \\
\hline S1 & $\begin{array}{l}\text { The ability to work well } \\
\text { in teams-especially } \\
\text { with people different } \\
\text { from yourself }\end{array}$ & $\begin{array}{c}3.31 \\
(S D=.78)\end{array}$ & $\begin{array}{c}3.43 \\
(\mathrm{SD}=.74)\end{array}$ \\
\hline S2 & $\begin{array}{l}\text { An understanding of } \\
\text { science and technology } \\
\text { and how these subjects } \\
\text { are used in real-world } \\
\text { settings }\end{array}$ & $\begin{array}{c}3.09 \\
(S D=.81)\end{array}$ & $\begin{array}{c}3.02 \\
(\mathrm{SD}=.89)\end{array}$ \\
\hline S3 & $\begin{array}{l}\text { The ability to write and } \\
\text { speak well }\end{array}$ & $\begin{array}{c}2.58 \\
(\mathrm{SD}=.84)\end{array}$ & $\begin{array}{c}2.89 \\
(\mathrm{SD}=.76)\end{array}$ \\
\hline S4 & $\begin{array}{l}\text { The ability to think } \\
\text { clearly about complex } \\
\text { problems }\end{array}$ & $\begin{array}{c}3.30 \\
(\mathrm{SD}=.73)\end{array}$ & $\begin{array}{c}3.30 \\
(\mathrm{SD}=.77)\end{array}$ \\
\hline S5 & $\begin{array}{l}\text { The ability to analyze a } \\
\text { problem to develop } \\
\text { workable solutions }\end{array}$ & $\begin{array}{c}3.50 \\
(\mathrm{SD}=.64)\end{array}$ & $\begin{array}{c}3.49 \\
(\mathrm{SD}=.77)\end{array}$ \\
\hline S6 & $\begin{array}{l}\text { An understanding of } \\
\text { global context in which } \\
\text { work is now done }\end{array}$ & $\begin{array}{c}2.68 \\
(S D=.96)\end{array}$ & $\begin{array}{c}2.55 \\
(\mathrm{SD}=1.16)\end{array}$ \\
\hline S7 & $\begin{array}{l}\text { The ability to be creative } \\
\text { and innovative in } \\
\text { solving problems }\end{array}$ & $\begin{array}{c}3.07 \\
(S D=.83)\end{array}$ & $\begin{array}{c}2.83 \\
(\mathrm{SD}=.97)\end{array}$ \\
\hline S8 & $\begin{array}{l}\text { The ability to apply } \\
\text { knowledge and skills in } \\
\text { new settings }\end{array}$ & $\begin{array}{c}3.48 \\
(S D=.70)\end{array}$ & $\begin{array}{c}3.38 \\
(S D=.70)\end{array}$ \\
\hline s9 & $\begin{array}{l}\text { The ability to } \\
\text { understand numbers } \\
\text { and statistics }\end{array}$ & $\begin{array}{c}2.29 \\
(\mathrm{SD}=.92)\end{array}$ & $\begin{array}{c}2.02 \\
(\mathrm{SD}=.98)\end{array}$ \\
\hline S10 & $\begin{array}{l}\text { A strong sense of ethics } \\
\text { and integrity }\end{array}$ & $\begin{array}{l}2.17 \\
(\mathrm{SD}= \\
1.01)\end{array}$ & $\begin{array}{c}2.49 \\
(\mathrm{SD}=1.18)\end{array}$ \\
\hline
\end{tabular}

A total of 115 students completed the INTEX assessment survey, comprised of a combination of juniors and seniors in the Bachelor of Information Systems program, as well as first- and second-year master students in the Master of Information Systems Management program. Each of the students would have participated in INTEX within the current or previous academic year. Eighty-five percent of respondents were males while the remaining fifteen percent were females. In addition to questions regarding the AACU skills, students were asked how well they got along with team members, how INTEX influenced career goals, how prepared they felt to complete each deliverable, and suggestions on how they would change INTEX.

Current IS students ranked six (S1, S2, S4, S5, S7, S8) of the ten AACU skills as being "enhanced" through participation in INTEX while the remaining four (S3, S6, S9, S10) were ranked as being "slightly enhanced" (see Table 1). All ten skills showed some level of enhancement.

The ability to analyze a problem to develop workable solutions (S5) ranked highest with $93.91 \%$ of students indicating that the skill was enhanced or greatly enhanced. Additionally, $89.56 \%$ of students responded that their ability to apply knowledge and skills in new settings was enhanced or greatly enhanced.

When asked how well students got along with their teammates, $57.80 \%$ of students said they got along very well, $33.03 \%$ said well, $6.42 \%$ said slightly well, and $2.75 \%$ indicated not well at all. Overall, $97 \%$ of students felt teams functioned "well" or better. Students provided explanations for their team ratings, and many responses indicated positive team interaction $(90.83 \%$ were well to very well), expressing praise and sincere concern for team members, as well as an increased appreciation for individual contributions and capabilities. Other responses revealed various struggles that team members faced.

Just over half of the students, $58.33 \%$, who participated in the survey, indicated that INTEX influenced their career goals. Several replies explained how the student discovered where his/her passion is, while others were able to eliminate certain career paths because of their INTEX experience.

In the survey results, $49.54 \%$ of students responded that they felt only slightly or not prepared at all to complete the feasibility analysis portion of the case. An additional $32.11 \%$ expressed that same sentiment regarding the presentation. Some groups said there was confusion and uncertainty in who their presentation audience would consist of, making it challenging to determine whether the terminology should consist of mostly technical or executive terms (see Figure 4).

In sifting through responses addressing suggestions on how to improve INTEX, topics that were repeatedly mentioned include the ambiguity of the case, difficulties with the time constraint, a request for additional feedback, and adjustments to the grading approach. Other comments suggested better preparation in certain technical areas, as well as presentation tips, assistance with group conflicts, and a proposal that INTEX be an alternative or replacement for final exams.

While the surveys were completed by a combination of IS juniors, seniors, and master students, only peer evaluations of IS juniors who participated in INTEX during Fall 2019 were reviewed. Responses consisted of dozens of statements conveying the positive impact INTEX had on the participants as well as an affirmation that this exercise successfully enhanced multiple learning areas. Even amidst negative feedback from students were concessions that it was a worthwhile experience. Many students expressed that they were able to deepen understanding of concepts that may have seemed elusive beforehand, and several 
commented that they now have a better grasp on how to solve real business problems.

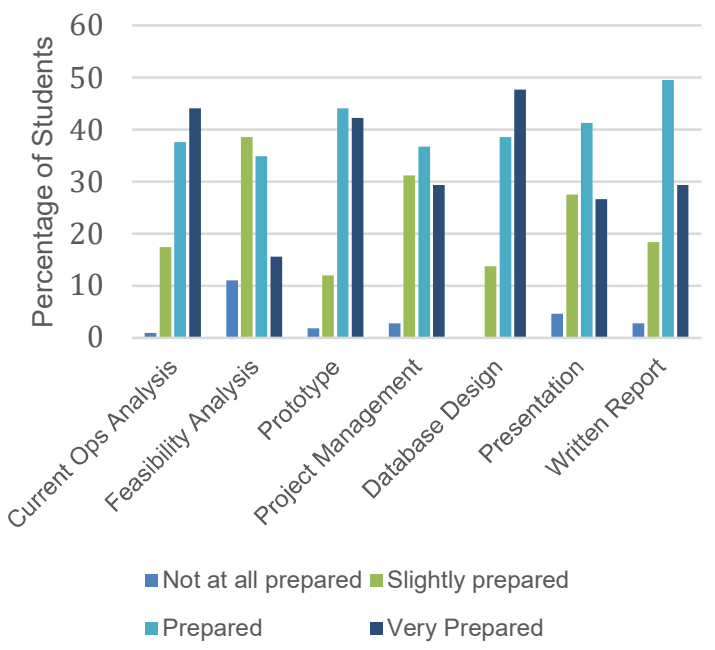

Figure 4. How prepared students felt to complete deliverables

\subsection{Alumni}

Alumni were also surveyed asking for indication as to how INTEX enhanced their development of the top ten employer desired skills. A total of 47 surveys were completed by alumni who had previously participated in INTEX. The elapsed time since participating in INTEX ranged from $0.5-18$ years, with an average of 7.9 years. Alumni were asked to reflect upon their INTEX experience using a scale of 1-10 with 1 being "does not remember the experience at all" and 10 being "remembers the experience very clearly/perfectly". Alumni responded with an average of 8.5 indicating most still remember the INTEX experience. Work experience of respondents ranged from 0 to 25 years with an average of 7.4 years. The majority, $37.93 \%$, of survey participants work in software development, and $38.6 \%$ are in management positions. Overall, alumni's perspectives of INTEX as a student were that the experience was challenging but benefited them tremendously. For some alumni, the appreciation grew as they entered the workforce.

Results from IS alumni showed that five (S1, S2, S4, S5, S8) of the ten skills were "enhanced" and the other five were "slightly enhanced." Thus, all ten skills were at least somewhat enhanced. The most highly selected skills alumni felt were enhanced or greatly enhanced by INTEX include: the ability to apply knowledge and skills in new settings (91.49\%), the ability to work well in teams $(89.36 \%)$, the ability to analyze a problem to develop workable solutions
$(87.23 \%)$, and the ability to think clearly about complex problems $(85.11 \%)$. The most highly selected skills alumni felt were not at all enhanced by INTEX include: the ability to understand numbers and statistics $(38.3 \%)$, a strong sense of ethics and integrity $(25.53 \%)$, and an understanding of global context in which work is now done $(23.4 \%)$.

The variability between alumni and current students merits further discussion. The greatest difference (.32) in mean scores from alumni versus current students is in S10, a strong sense of ethics and integrity, with alumni having a higher rank. Students ranked the ability to be creative and innovative in solving problems (S7) and the ability to understand numbers and statistics (S9) higher than alumni did with differences of -.24 and -.27 respectively. One plausible reason for these differences is the perspective in which INTEX is viewed in hindsight, especially after being involved in real-world cases.

The alumni mean for the AACU skill regarding the ability to work in teams (S1) was .10 higher than that of the current students' mean; this could indicate that as alumni entered the workforce and began working with teams consistently, they further understood how INTEX had enhanced their ability to do so effectively. S3, the ability to write and speak well, was ranked higher by alumni in comparison to current students with a mean difference of .31. This may suggest that, as alumni have progressed to their careers, they've come to see how INTEX enhanced their ability to write and speak well more than previously thought.

Of the aspects of INTEX that were most and least applicable and realistic to their day-to-day jobs, most alumni mentioned working in teams and meeting deadlines was most realistic while learning skills such as Unified Modeling Language (UML) diagramming was least realistic. Whether or not other aspects of INTEX, such as presenting, documenting, programming, etc., were applicable depended upon what field(s) the alumni had worked in. For example, those with development positions indicated that the documentation (systems requirements gathering and diagramming) aspects of INTEX are not highly applicable in their work responsibilities. However, several respondents agreed that the requirements of their INTEX case are much more specific than projects they've worked on in their careers.

\subsection{Instructors}

The survey administered to INTEX instructors differed from the survey students and alumni completed. In the survey, IS faculty were asked about their perceptions of INTEX as a student (if they participated in INTEX while a student), as an IS 
professional, and as a professor. We received a total of eight responses, all of which spoke positively of INTEX. One professor noted, "While a student, it was hard and required long hours. In retrospect, it quickly became one of the highlights of my undergraduate experience. Invaluable for seeing how things connected."

Professors were asked if they are advocates for or against INTEX and to explain why. The overall response was an advocacy for INTEX; in their arguments, instructors listed many of the skills students develop including confidence, dependence on others, teamwork, and preparation for the real world as well as the opportunity to "coalesce the knowledge students have acquired over the classes and then go through the cycle again in a relatively short amount of time." One professor mentioned that while he is an advocate for INTEX, it can be difficult for faculty to coordinate.

Faculty were also asked to provide any recommendations on how INTEX can be improved. Responses focused mainly on administrative adjustments such as how materials are presented to judges, providing more guidelines for presentations, and implementing a daily time cap so students may only work on INTEX for a maximum number of hours per day.

\section{Discussion}

Each of the seven objectives of INTEX was measured based on the results previously outlined. The following is a discussion of our findings including the extent to which each of the objectives was fulfilled.

\subsection{Demonstrate how principles are synergistically applied to a real world case}

Eight (S2, S4, S5, S6, S7, S8, S9, S10) of the top ten skills employers seek in new college graduates were used to measure this first objective. Of those selected eight skills, INTEX is successful in enhancing or greatly enhancing four (S2, S4, S5, S8), demonstrating that the design of the exercise provides an accurate and effective simulation of a real-world case.

The remaining four skills (S6, S7, S9, S10) were also positively impacted through INTEX, being slightly enhanced. These skills are largely influenced by the case given. Cases that necessitate extensive math skills or involve ethical issues may have a greater impact on perceived understanding of numbers and statistics (S9) or a strong sense of ethics and integrity (S10). An understanding of the global context in which work is done is also likely influenced by the case topic (S6).

\subsection{Simulate an "on-the-job" teamwork experience}

Through the quantitative data collected from the surveys regarding S1, INTEX appears to be successful in providing students a significant teamwork experience, and the qualitative data from surveys and peer evaluations further validate this conclusion. A high percentage of current students functioned well within their teams but a low number $(9.17 \%)$ said they got along with their team either "slightly well" or "not at all" (see Figure 5).

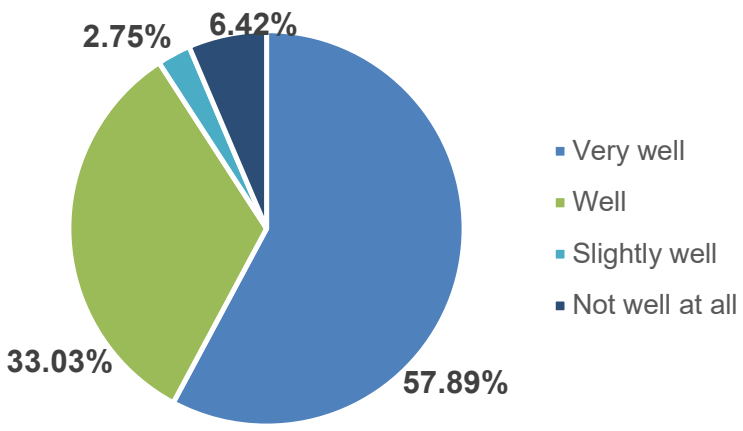

Figure 5. How well students felt their teams worked together

The challenges faced by these teams included: one member doing most of the work, students feeling sidelined by teammates, scheduling conflicts, teammates lacking necessary skills, etc. The faculty recognize these struggles and while they are not treated lightly, they also acknowledge that the conflicts between team members further simulates "on-the-job" experiences often faced in the business world. The principles gleaned from these experiences may benefit the members of struggling teams in the future more than those of teams who thrived together.

\subsection{Create an opportunity for students to practice technical and soft presentation skills}

Although the ability to write and speak well (S3) generated a lower mean by both current students and alumni in comparison to the other AACU skills, INTEX successfully provides an opportunity to practice these communication skills as expressed in the objective.

The large percentages of students who indicated they felt only slightly or not at all prepared for the presentation (32.11\%) portion of INTEX suggest that students should be provided with additional instruction regarding these skills prior to completing INTEX. 


\subsection{Provide students with performance feedback}

Complaints among student survey responses regarding issues such as an overall insufficient amount of feedback, subjective feedback from judges, and vague grading criteria suggest a need for improvement in order to maximize students' INTEX experience.

Though evaluation panels provide immediate feedback to each group during the debriefing following their presentation, some panels may be more critical or lenient with each requirement on the evaluation form. Students are only given a grade percentage for their INTEX project, though they may request more specific feedback from professors or TAs. Clarifying grading requirements for future INTEX may necessitate providing a more explicit grading rubric in the future.

\subsection{Create an experience students can reference as they pursue future careers}

As suggested by the data, INTEX is a very memorable experience for students, allowing them to reference it in years to come. As one alumnus who experienced INTEX 13 years ago stated, "I am still talking about it and how it helped prepare me.... I think it was instrumental and helpful in helping me as a student and preparing me for some of the things that I would be asked to do as an employee."

The results confirmed that, for most, INTEX played a valuable role in their preparation for the workforce. One alumnus said, when asked how his/her perspective of INTEX changed upon entering the workforce, "[It was] truly was much closer to what I actually do at work than most other activities in school. Struggling with a group is real, struggling with abstract problems is real, running into roadblocks is real."

Not only does INTEX provide the context for students to reference in their careers, but also helps set them apart from other candidates. An alumnus of the IS program said, "Now that I'm an employer making hiring decisions, knowing that an applicant had successfully completed such a rigorous project would make that applicant stand out."

\subsection{Establish a measurement of comprehensive student learning for faculty}

Professors have created and regularly refine a rigorous grading rubric to determine whether or not learning was successful. The rubric assesses multiple learning outcomes for each class that comprises the INTEX project, giving each instructor a chance to get data specific to their own instructional effectiveness. Student INTEX grades consistently fall between $85-$ $95 \%$, indicating that INTEX is successful in leading to comprehensive learning. Through assessing the projects and presentations, faculty have an effective way to measure student learning.

\subsection{Provide feedback to IS faculty for further curriculum development}

Faculty derive feedback regarding INTEX from three main sources: grading rubrics, student evaluation forms, and advisory judges. Using this feedback, faculty gather in a post-INTEX review to evaluate how well the students learned each topic and if course curriculum adjustments are needed for future semesters.

The grading rubrics and student evaluation forms were previously discussed, so this section will focus specifically on feedback from advisory judges and the post-INTEX review.

Advisory judges give students feedback immediately following their presentations, but they also discuss their observations with faculty members. The relevance of judges' industry experience provides a valuable perspective on student performance in relation to workforce application.

The post-INTEX faculty review, though informal, has been used to assess the provided feedback and discuss program improvements. For example, a common request found in the student feedback pertained to the final exams, which take place shortly after INTEX. Students felt that INTEX was an applied final exam, which made the final exams feel like less crucial memorization tests. Recently, due this student feedback, the faculty decided to replace the final exams in the core classes with the INTEX project as an added reflection paper. Another curriculum improvement came from student and judge feedback about lack of presentation skills and preparedness, causing the faculty to add a "Presentations" chapter to one of the courses to help guide the students.

Using the evaluation of INTEX performance as a method of improving IS curriculum has been successful, though a more extensive and formal review could potentially take greater advantage of the insights INTEX participation offers on student learning and performance.

\section{Conclusion}

Our appraisal of INTEX as an experiential learning model and of the current methodology in attaining the outlined objectives revealed success in providing a 
comprehensive, real world project; providing a realistic teamwork experience; creating an opportunity to apply technical and soft presentation skills; supplying a context for reference in advanced pursuits; serving as a measurement for comprehensive learning; and providing feedback to foster program development.

Through the achievement of these objectives and acquisition of AACU skills, INTEX has played an invaluable role in student and program development. As one student said, "Nothing in a class can substitute for the things that we learned [in INTEX] week. To just be given a problem and [have to] decide ourselves how to solve it all on our own was such a valuable experience that I am so grateful for." Another student said "I feel much more prepared to enter the industry and actually make an impact. I know there is still a lot I have to learn, but I realized how much I can teach myself and that with determination I can do what I set my mind to."

Based on program goals, other institutions may consider adjustments in grading, the provisioned cases, and the time frame of INTEX. Modifications for remote instruction may also be considered.

In regard to grading, the following alternatives are plausible: making INTEX a higher weight in final grade, have INTEX replace final exams altogether, have the faculty grade the project, etc.

For the case outlining the problem to be solved, the following alternatives have been suggested to further simulate on-the-job experience: propose several case options for students to vote on, use a problem that a company currently needs solved, have the company change their mind about an aspect of the project part way through the week, etc.

In assessing the value of INTEX, one might also want to consider how it affects and aids students as they progress toward more advanced classes (L. McKell, personal communication, April 21, 2020).

The 2020 COVID-19 global pandemic forced faculty to consider how INTEX could be administered remotely. Instructors made the following adjustments to the experience while still preserving its most important aspects: students were required to do all work remotely but as a group using tools like Microsoft Teams, Zoom, and Slack; for the presentation, students were required to submit a 15 -min video recording; evaluation panels were each given several videos to watch and submit their feedback to the professors; the kickoff meeting and award ceremony was done via Zoom. Each team determined how to collaborate remotely, and the majority of teams used Zoom.

INTEX has been described as hard, challenging, exhausting, tough, intimidating, and intensive; it's also been described as fun, valuable, realistic, fantastic, exciting, and worthwhile. As one student summarized,
"I believe this to be one of the most fulfilling experiences of my life."

\section{References}

[1] Ali-Hassan, Hossam \& Bliemel, Michael (2014). GameBased Experiential Learning in Online Management Information Systems Classes Using Intel's IT Manager 3. https://jise.org/Volume25/n2/JISEv25n2p117.pdf.

[2] Association of American Colleges \& Universities. (2018, Jul.). 2018 Employer Research Report. Association of American Colleges \& Universities.

https:/www.aacu.org/sites/default/files/files/LEAP/2018Em ployerResearchReport.pdf.

[3] Association of American Colleges \& Universities. (2014, Sept. 11). Top Ten Things Employers Look For in New College Graduates. Association of American Colleges \& Universities. www.aacu.org/leap/students/employers-topten.

[4] Atkinson, George Jr. \& Murrell, Patricia H. (1988). Kolb's Experiential Learning Theory: A Meta-Model for Career Exploration, Journal of Counseling and Development (66). https://onlinelibrary.wiley.com/doi/abs/10.1002/j.15566676.1988.tb00890.x.

[5] Fathelrahman, Adil \& Kabbar, Eltahir (2018)

Conceptualization of enterprise systems education using an experiential learning framework, Journal of Education for Business, 93:2, 46-50, DOI:

10.1080/08832323.2017.1417230

[6] Heim, Gregory R.; Meile, Larry; Tease, Justin; Glass, Jeff; Laher, Sahal; Rowan, James; and Comerford, Katie (2005) "Experiential Learning in a Management Information Systems Course: Simulating IT Consulting and CRM System Procurement," Communications of the Association for Information Systems: Vol. 15, Article 25. DOI:

10.17705/1CAIS.01525.

https://aisel.aisnet.org/cais/vol15/iss1/25

[7] Kolb, David A (1984). Experiential Learning:

Experience as The Source of Learning and Development. https://learningfromexperience.com/downloads/researchlibrary/the-process-of-experiential-learning.pdf.

[8] Kolb's Learning Cycle [Digital image]. (2018, June 19). Retrieved September 29, 2020, from

https://www.inspiring.uk.com/how-to-create-effectivelearning-within-your-organisation/kolbs-learning-cycle/. [9] McCarthy, Mary. (2016). Experiential Learning Theory: From Theory To Practice, Journal of Business \& Economics Research, 14(3).

https://www.clutejournals.com/index.php/JBER/article/view/ 9749/9838.

[10] McKell, Lynn J (2008). Direct Assessment of IS

Student Learning Using an Integrative Exercise, Journal of Information Systems Education, 19(2).

https://eric.ed.gov/?id=EJ831375. 